\title{
Prediction of Microbial Enhanced Oil Recovery using an Artificial Intelligence Method based on Experimental Data
}

\author{
Payam Alikhani \\ Department of Science and \\ Technology, University of \\ Algarve, Faro, Portugal
}

\author{
Seyyed Mohammadreza \\ Hesami \\ Department of Chemical \\ Engineering, Petroleum \\ University of Technology, \\ Ahwaz, Iran
}

\author{
Abdolnabi Hashemi \\ Department of Petroleum \\ Engineering, Petroleum \\ University of Technology, \\ Ahwaz, Iran
}

\begin{abstract}
Enhanced oil recovery (EOR) process may be used to recover additional oil left in place after primary recovery. The prediction of its performance is of great importance in the selection and design of a certain EOR process, and also within planning of oil production.

In this paper, in order to study the ability of four specific microorganisms consisting of pseudomonas aeruginosa, bacillus subtilis, bacillus licheniformis and clostridium acetobutylicium for enhanced oil recovery over 5 Iranian reservoirs, a model of artificial neural network (ANN) has been built by using of 83 Laboratory data with valid reference. Each one of these data consists of six parameters including porosity, permeability, pressure, temperature, salinity and $\mathrm{PH}$ which have been devoted to network as inputs. Also, the related oil recovery of each data which has gained base on the effects of utilized microorganism and six parameters has used as output. After that, this model base on four microorganisms has been used for predicting oil recovery percent of five different reservoirs, whereas the property of these new reservoirs entered as our new inputs. The result of our study showed the ability of bacillus subtilis in comparison with other three microorganisms over these five reservoirs on account of its comparatively high oil recovery percent that varies between 37.7- 50.3 for different reservoirs.
\end{abstract}

\section{General Terms}

Artificial neural network (ANN), Microbial Enhanced Oil Recovery (MEOR), microorganism

\section{Keywords}

Enhanced Oil Recovery, Microbial, bacillus subtilis, neural network

\section{INTRODUCTION}

Naturally, oil is produced from reservoir by its potential energy or pressure gradient between surface and subsurface condition, when this energy reduced, attention has been focused on the Enhanced Oil Recovery (EOR) techniques for recovery more oil from the existing and abandoned oil fields. The EOR methods may be divided to three categories: thermal, chemical and gas injection methods. Thermal method will be applied for heat needs of reservoirs. This method includes steam or hot water injection and in situ combustion technique. Chemical flooding involves injection of certain chemicals that might change either the characteristics of the reservoir fluids or improve the oil recovery mechanisms. These include polymer, surfactants, alkaline flooding and miscible flooding (either first-or multi -contact miscible) includes $\mathrm{CO}_{2}$ miscible gas injection, $\mathrm{N}_{2}$ miscible injection and others. On the other hand more advanced technologies are being employed in the oil industry to recover the trapped oil. These include seismic and sonic stimulation and electromagnetic methods [2], [13]. Figure 1 shows the types of EOR progresses that are currently employed in the oil industry. Choosing best method among different EOR techniques is difficult, important and depends on major effective parameters. We start this investigation with emphasis on Microbial Enhanced Oil Recovery (MEOR) and we want to know which microbes and which structure of modeling is better and more effective?

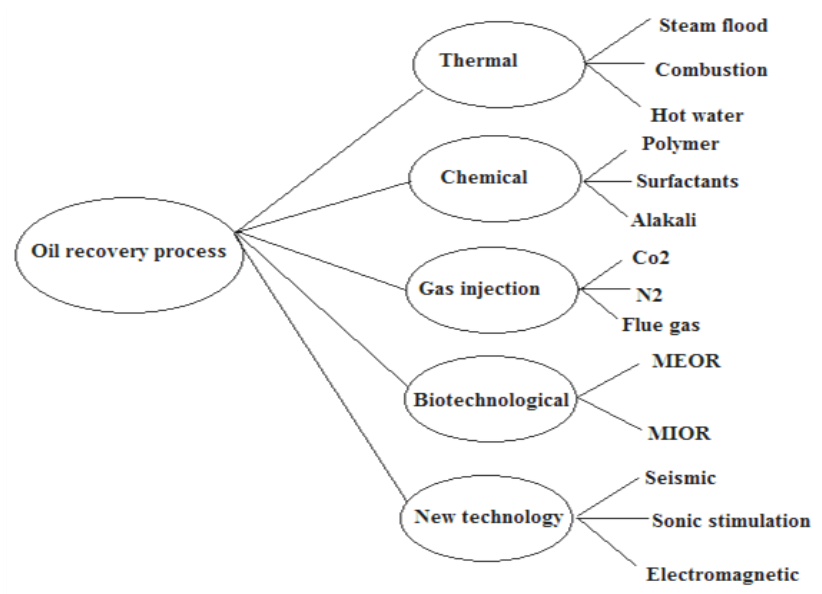

Fig 1: Different methods for enhanced oil recovery (EOR) [16]

In 1940 ZoBell and his coworkers started a series of organized laboratory investigations on using of microorganisms for releasing oil from porous media. Their results showed the beginning of a new period of research in petroleum microbiology with application for oil recovery industry [5].

Microbial enhanced oil recovery (MEOR) could be applied in oil reservoirs using ex-situ and in-situ methods. In ex-situ recovery methods, microbes are cultured in industrial laboratories and then the microbes and their products are injected into the oil bearing formations using water-flooding methods. The in-situ method is categorized to microbial flooding method and stimulation of single wells. Microbial flooding method uses the microorganisms and the nutrition in water flooding while in stimulation of wells the anaerobic microorganisms are injected into the wells and then the wells are shut off for days or weeks so that the porous medium is soaked [6]. 
MEOR has many benefits such as economical, low toxicity biodegradability and biocompatibility, selectivity, specificity at high temperature, $\mathrm{pH}$ and salinity [2]. There are three mechanisms for enhance oil recovery by microorganisms: a) Microorganisms can produce some metabolites such as biosurfactans and biopolymers that decrease surface tension. b) Microorganisms can produce some gases such as $\mathrm{CH} 4$, $\mathrm{CO} 2$ to recover trapped oil. c) Microorganisms can selectively plug high permeability channel into reservoir. Table 1 shows the summary of these metabolites and their applications in MEOR [14].

Table 1. Microbial consortia and their metabolites with applications in MEOR [2]

\begin{tabular}{|c|c|c|}
\hline $\begin{array}{c}\text { Microbial } \\
\text { metabolites }\end{array}$ & Microbe type & $\begin{array}{l}\text { Application in } \\
\text { MEOR }\end{array}$ \\
\hline Biomass & $\begin{array}{l}\text { Bacillus } \\
\text { licheniformis, } \\
\text { leuconostoc } \\
\text { mesenteroides, } \\
\text { Xanthomonas } \\
\text { campestris }\end{array}$ & $\begin{array}{l}\text { Selective plugging and } \\
\text { wettability alteration }\end{array}$ \\
\hline $\begin{array}{c}\text { Bio- } \\
\text { Surfactant }\end{array}$ & $\begin{array}{l}\text { Acinetobacter, } \\
\text { Arthrobacter, } \\
\text { Bacillus, } \\
\text { Pseudomonas }\end{array}$ & $\begin{array}{l}\text { Emulsification and de- } \\
\text { emulsification through } \\
\text { reduction of interfacial } \\
\text { tension }\end{array}$ \\
\hline $\begin{array}{l}\text { Bio- } \\
\text { Polymer }\end{array}$ & $\begin{array}{c}\text { Bacillus, } \\
\text { Brevibacterium, } \\
\text { Leuconostoc, } \\
\text { Xanthomonas } \\
\end{array}$ & $\begin{array}{l}\text { Injectivity profile and } \\
\text { viscosity modification, } \\
\text { selective plugging }\end{array}$ \\
\hline Bio-Solvent & $\begin{array}{l}\text { Clostridium, } \\
\text { Zymomonas, } \\
\text { klebsiella }\end{array}$ & $\begin{array}{l}\text { Permeability increase, } \\
\text { oil viscosity reduction }\end{array}$ \\
\hline Bio-Acids & $\begin{array}{c}\text { Clostridium, } \\
\text { Enterobacter, Mixed } \\
\text { acidogens }\end{array}$ & $\begin{array}{c}\text { Permeability increase, } \\
\text { emulsification }\end{array}$ \\
\hline Bio-Gases & $\begin{array}{c}\text { Clostridium, } \\
\text { Enterobacter, } \\
\text { Methanobacterium }\end{array}$ & $\begin{array}{l}\text { Increased pressure, oil } \\
\text { swelling, interfacial } \\
\text { tension and viscosity } \\
\text { reduction, } \\
\text { Permeability increase, }\end{array}$ \\
\hline
\end{tabular}

In this study tried to develop a model by artificial neural network (ANN) that known as a novel mathematical tools in order to find the ability of special microorganisms over five Iranian reservoirs. Mathematical models are required to describe the MEOR process in a better way. MEOR modeling developed in reservoir engineering over the past two decades. So in our network different parameters that effect on oil recovery was used as input of network and oil recovery percentage was used as output. By this model, the prediction of oil recovery of five different reservoirs in the presence of microorganisms has been done. Ultimately, we obtain some amazing and reasonable results.

\section{ARTIFICIAL NEURAL NETWORK DEFINITION}

An Artificial Neural Network (ANN), usually called neural network (NN), is a mathematical model that is inspired by the structure and/or functional aspects of biological neural networks. A neural network is a computing tool that consists of an interconnected group of artificial neurons, and it processes information using a connectionist approach to computation. Modern ANNs are non-linear statistical data modeling tools. This method is also successful in issues such as clustering, classification, model complex relationships between inputs and outputs function forecast and prediction
[3]. ANN have already been successfully applied in many industries, in fact, it is particularly useful in applications where the complexity of the data or task makes the design of such a function by hand impractical. Application areas include game playing and decision making [10] such as poker, sequence recognition such as face recognition [8] neurology and psychology quantum chemistry [4] and so on.

A first wave of interest in neural network (also known as 'connectionist models' or 'parallel distributed processing') emerged after the introduction of simplified neurons in 1943 [13]. The model that was created had two inputs and a single output. These neurons were presented as models of biological neurons and as conceptual components for circuits that could perform computational tasks so the term neural network was traditionally used to refer to a network or circuit of biological neurons [7]. After that perceptron was published in 1958 [12] (The perceptron is a very simple mathematical representation of the neuron), research into neural networks went unfunded, and would remain so, until a method was developed to solve n-separable problems because of a perceptron could then only solve a 2- separable or a linearly separable problems. In 1974 the algorithm of back propagation was developed [15] and then independently rediscovered. Back propagation is a form of the gradient descent algorithm used with artificial neural networks for minimization and curve fitting. In the way of introducing with back propagation we consider a multilayer perceptron like Figure 2 with $\mathrm{L}$ interlayer. Each interlayer has $N_{l}$ node and $N_{l} \times N_{l-l}$ connection with weight $\mathrm{w} \in \mathrm{R}_{l}^{N \times N}{ }_{l-l}$. By the way $N_{l}$ and $N_{l-l}$ are the number of nodes (including biases) in interlayers $l$ and $l-1$, respectively.

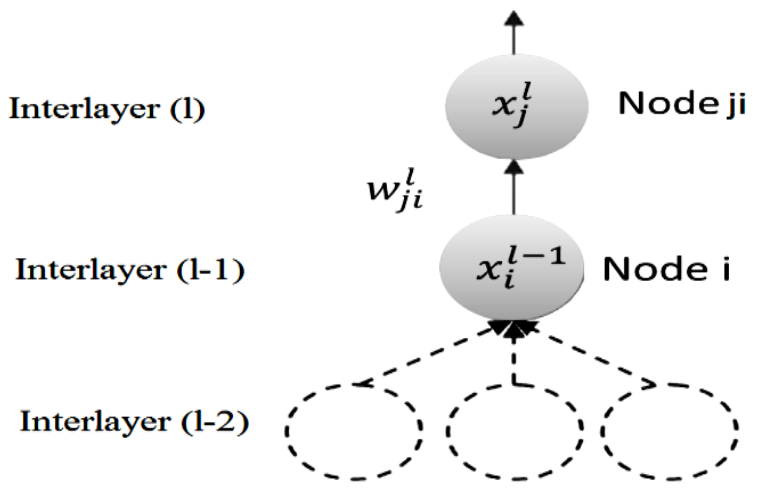

Fig 2: Notation used in back propagation

All neural networks consist of three main layers that are called input, hidden and output layers. All types of these (ANN) architectures consist of same elements such as nodes, layers and connections. However, some of them like multi-layer perceptron and radial basis function are more popular [10], [11].

\section{MATERIAL AND METHOD}

It is necessary to train an ANN before using it for a specific application. Training is the act of presenting the network with some sample data and modifying the weights and biases to better approximate the desire function. Among the available methods to train a neural network and learning in multilayer networks, the back propagation method is most popular used [9], [16] and is a form of supervised training, this form (supervised training) first supplies the neural network with inputs and the desired outputs, after that the weights are modified to reduce the difference between the actual and desired outputs. 
Before training and also testing any neural network, data sets must be normalized into a range of $0.1-0.9,[1]$ so equation 1 was used to scale outputs and inputs:

$($ scaled $)$ value $=\frac{(\text { Actual }) \text { value }- \text { minimum }(\text { Actual value })}{\text { maximum }(\text { Actual value })-\text { minimum }(\text { Actual value })} \times 0.8+0.1$ (1)

As comparison criteria, mean square error (MSE), correction coefficient $(\mathrm{R})$ and $\mathrm{R}^{2}$ was used. MSE, $\mathrm{R}$ and $\mathrm{R}^{2}$ formulas that were used in this study were given according to equations 2,3 and 4:

$$
\begin{gathered}
\mathrm{MSE}=\frac{1}{\mathrm{~N}} \sum_{\mathrm{i}=1}^{\mathrm{N}}\left(\mathrm{y}_{\mathrm{i}}-\mathrm{y}_{\mathrm{i}}^{\exp }\right)^{2} \\
\mathrm{R}=\frac{\sum(y-Y)(y \exp -Y \exp ) 2}{\sqrt{\sum(y-Y) 2 \sum(y \exp -Y \exp ) 2}} \\
\mathrm{R}^{2}=\frac{\sum_{i=1}^{N}(y \exp -Y) 2-\sum_{i=1}^{N}(\mathrm{yiexp}-y i) 2}{\sum_{i=1}^{N}(y \exp -Y) 2}
\end{gathered}
$$

Here $\mathrm{N}$ states the total data number, $\mathrm{y}_{\mathrm{i}}$ is the value of recovery that predicted by $\mathrm{NN}, \mathrm{y}_{\mathrm{i}}^{\text {exp }}$ is the experimental data that used as target for training the NN, Y exp is the average of the experimental data and $Y$ is the average of the NN's result.

In our study network's layers and neurons are chosen by trial and error, for example neurons of hidden layer are changed from 1 to 18 for choosing the best neuron.

In order to programming, validation, training and testing of ANN model, NN manual codes of MATLAB version 7.10.0.499 (R2010a) were used. All of our 83experimental data have been divided into three parts randomly; $80 \%$ was used for training, $10 \%$ for validation and $10 \%$ for testing. The diagram of recovery as output of 83 laboratory data shown in Figure 3, and input of this data exists in our data-reference separately for microbes. The total number of inputs was six including: porosity $(\%)$, permeability $(\mathrm{md})$, pressure (psi), temperature (F), salinity (\%) and $\mathrm{PH}(0-14)$. Figure 3 shows a schematic of our network.

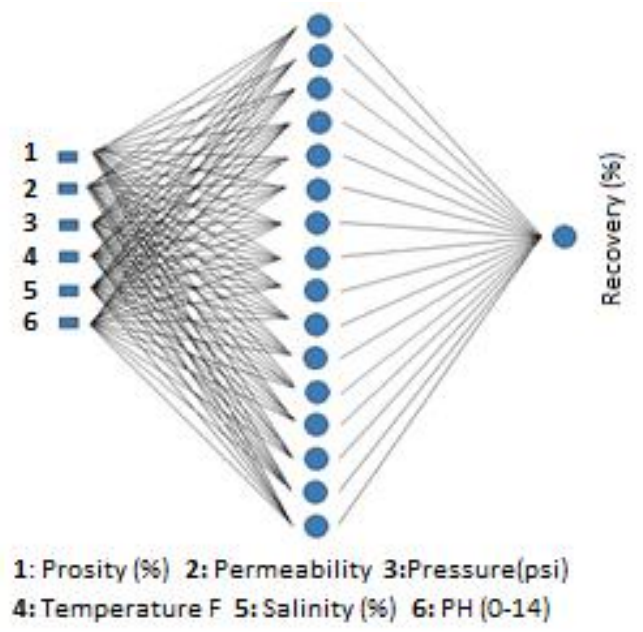

Fig 3: Neural network architecture used for oil recovery prediction

The purpose of this section is developing of ANN model based on laboratory data and then prediction of oil recovery percent for 5 special reservoirs. As inputs of optimized modeling, properties of five different reservoirs shown in Table 2 entered and five outputs as oil recovery prediction obtained for every four microbes.
Table 2. Reservoir properties

\begin{tabular}{|c|c|c|c|c|c|}
\hline Properties & $\begin{array}{c}\text { Res. } \\
\text { No.1 }\end{array}$ & $\begin{array}{c}\text { Res. } \\
\text { No.2 }\end{array}$ & $\begin{array}{c}\text { Res. } \\
\text { No.3 }\end{array}$ & $\begin{array}{c}\text { Res. } \\
\text { No.4 }\end{array}$ & $\begin{array}{c}\text { Res. } \\
\text { No.5 }\end{array}$ \\
\hline $\begin{array}{c}\text { Porosity } \\
(\%)\end{array}$ & 22.3 & 11.4 & 12 & 6.8 & 9.6 \\
\hline K (md) & 5.2 & 16.85 & 2 & 800 & 1.6 \\
\hline P (psi) & 3553 & 4869 & 3623 & 6443 & 4258 \\
\hline T (F) & 178 & 171 & 185 & 181 & 141 \\
\hline $\begin{array}{c}\text { Salinity } \\
(\mathrm{ppm})\end{array}$ & 215000 & 130000 & 200000 & 270000 & 200000 \\
\hline PH & 6.7 & 6.33 & 7 & 5.3 & 6.5 \\
\hline
\end{tabular}

\section{RESULTS AND DISCUSSION}

To obtain the best network performance, the optimal network architecture and parameters must be chosen. Studies of the network structures include the selection of the number of layer and the number of neuron in each layer. The number of layer that was used for this neural network modeling was three, including: Input layer, one hidden layer and output layer. As can be seen from Figure 3, sixteen neurons were used in hidden layer and one neuron in the output layer.

In this work, a multi-layer feed-forward neural network has been used. Therefore, a brief description of this type of architecture will be given first. This optimum three layers feed forward network has been designed with sigmons hidden neurons and linear output neurons (newfit), also ANN has been trained with Levenberg-Marquardt back propagation algorithm (trainlm). The various neural network models which have the logistic function were trained and tested. In this step, the number of neuron in hidden layer of the network was determined by performance evaluating of the defined network models. As are shown in Table 3, the NN with 16 neurons in hidden layer has had the best performance on the all of data sets, so it was selected and used as neural network model to predict oil recovery in 5 reservoirs. Figure 4 shows oil recovery for different microorganisms as output of laboratory's data.

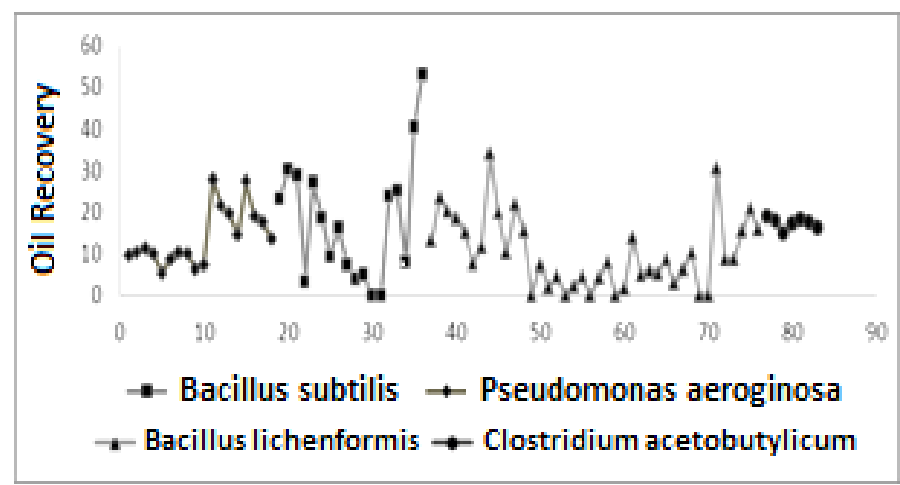

Fig 4: Oil recovery for different microorganism

In Figure 5, the correlation between the optimum network estimations and experimental data is illustrated with best linear fit and the correlation coefficient 0.85 for different microorganisms. Prediction results of oil recoveries using above optimum network are also shown in Table 4 that the most oil recovery was obtained in $1^{\text {st }}$ reservoir. 
Table 3: Results of ANN modeling with different neuron

\begin{tabular}{|c|c|c|c|c|c|c|c|c|}
\cline { 2 - 9 } \multicolumn{1}{c|}{} & \multicolumn{2}{c|}{ Train } & \multicolumn{2}{c|}{ Validation } & \multicolumn{2}{c|}{ Test } & \multicolumn{2}{c|}{ All } \\
\cline { 2 - 9 } \multicolumn{1}{c|}{} & MSE & R & MSE & R & MSE & R & R & R $^{2}$ \\
\hline 12- Neuron & 0.005397 & 0.8758 & 0.020073 & 0.9236 & 0.004206 & 0.9048 & 0.8404 & 0.7063 \\
\hline 13- Neuron & 0.006473 & 0.8686 & 0.004994 & 0.8849 & 0.007877 & 0.9257 & 0.8472 & 0.7178 \\
\hline 14- Neuron & 0.003905 & 0.8993 & 0.014490 & 0.7296 & 0.008955 & 0.8952 & 0.8739 & 0.7636 \\
\hline 15- Neuron & 0.003143 & 0.9272 & 0.001791 & 0.9636 & 0.020969 & 0.7591 & 0.8913 & 0.7945 \\
\hline 16- Neuron & 0.002566 & 0.9455 & 0.003411 & 0.9338 & 0.010046 & 0.8894 & 0.9245 & 0.8547 \\
\hline 17- Neuron & 0.004473 & 0.8906 & 0.006044 & 0.8774 & 0.002075 & 0.9757 & 0.8992 & 0.8085 \\
\hline 18- Neuron & 0.002920 & 0.9026 & 0.018192 & 0.9334 & 0.007585 & 0.8530 & 0.8932 & 0.7978 \\
\hline 19- Neuron & 0.006027 & 0.8489 & 0.003003 & 0.9256 & 0.015913 & 0.8788 & 0.8461 & 0.7158 \\
\hline
\end{tabular}

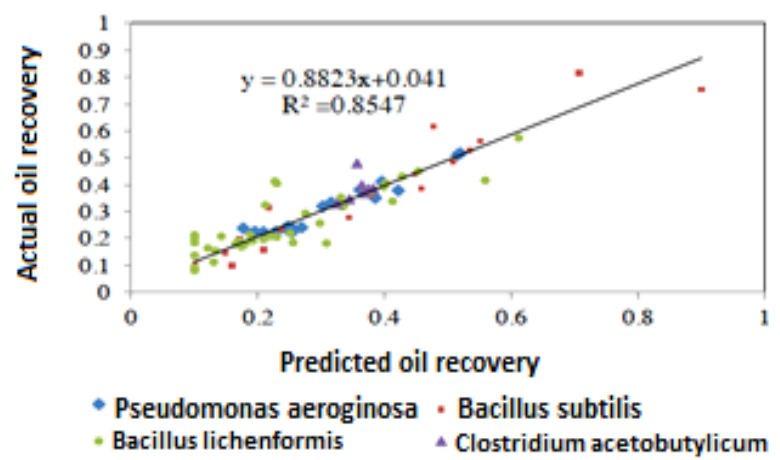

Fig 5: Actual oil recovery versus predicted oil recovery for different microorganisms

Table 4. Results of ANN prediction with different reservoirs and microorganisms

\begin{tabular}{|c|c|c|c|c|c|}
\hline $\begin{array}{c}\text { Microbe } \\
\text { Types }\end{array}$ & $\begin{array}{c}\text { Oil } \\
\text { recovery } \\
\text { in 1st } \\
\text { reservoir }\end{array}$ & $\begin{array}{c}\text { Oil } \\
\text { recovery } \\
\text { in 2st } \\
\text { reservoir }\end{array}$ & $\begin{array}{c}\text { Oil } \\
\text { recovery } \\
\text { in 3st } \\
\text { reservoir }\end{array}$ & $\begin{array}{c}\text { Oil } \\
\text { recovery } \\
\text { in 4st } \\
\text { reservoir }\end{array}$ & $\begin{array}{c}\text { Oil } \\
\text { recovery } \\
\text { in 5st } \\
\text { reservoir }\end{array}$ \\
\hline $\begin{array}{c}\text { Pseudomonas } \\
\text { aeroginosa }\end{array}$ & 47.7 & 29.8 & 24 & 37 & 14.5 \\
\hline Bacillus subtilis & 50.3 & 49.1 & 44.4 & 40.5 & 37.7 \\
\hline $\begin{array}{c}\text { Bacillus } \\
\text { lichenformis }\end{array}$ & 35.5 & 10.3 & 8.3 & 31.1 & 3.05 \\
\hline $\begin{array}{c}\text { Clostridium } \\
\text { acetobutylicum }\end{array}$ & 40.5 & 37.9 & 34.5 & 36.9 & 31.7 \\
\hline
\end{tabular}

\section{CONCLUSION}

In this work the ability of microbial enhanced oil recovery by using of specific microorganisms consisting of pseudomonas aeruginosa, bacillus subtilis, bacillus licheniformis and clostridium acetobutylicium over five Iranian reservoirs has been studied. Addition to above comparing between different reservoirs and microbes, this conclusion generally show that MEOR can be one of the best candidates among EOR techniques for these carbonate reservoirs. According to the result, from among these four microorganisms, the bacillus subtilis has have the better performance over five special reservoirs. In fact, its high ability has been inferred from its high range of oil recovery related to different reservoirs. Oil recovery percentage of bacillus subtilis varies between 37.750.3 for different reservoirs.

As a matter of fact, these special microorganisms have been utilized because of their biocompatibility, selectivity and specificity at high temperature, $\mathrm{pH}$ and salinity.

\section{REFERENCES}

[1] Aktas, A. H. and S. Yasar., 2004, "Potentiometric titration of some hydroxylated benzoic acids and cinnamic acids by artificial neural network calibration", Acta chimica slovenica51 (2): 273-282.

[2] Al-Sulaimani, H., S. Joshi, et al., 2011, "Microbial biotechnology for enhancing oil recovery: Current developments and future prospects", society for applied biothencnology, 1(2):147-158, India.

[3] Dursun, M. and M. Karaman, 2009, "Artificial neural network based modeling of spatial distribution of phosphorus on the tomato area", Asian Journal of Chemistry 21(1): 239-247.

[4] Ghosh, S. and A. Swer., 2010, Modelling of the Breakdown Voltage of Solid Insulating Materials using Soft Computing Techniques, B.S. Project, National institute of technology, Rourkela. 
[5] Hitzman, D.O. and Sperl, G.T., 1994, "New microbial technology for enhanced oil recovery and sulfide prevention and reduction", SPE/DOE 27752, Proceedings of the 9th Sympossium on Improved Oil Recovery, Society of Petroleum Engineers, Richardson, Texas.

[6] Mohamadizadeh, S.,SalehizadehH., 2007, "Microbial enhanced oil recovery using biosurfactant produced by Alcaligenesfaecalis", $5^{\text {th }}$ Biotech. Congress, Tehran, Iran.

[7] Hopfield, J. J. 1982, "Neural networks and physical systems with emergent collective computational abilities." Proceedings of the national academy of sciences 79(8): 2554.

[8] Le, T. H. 2011, "Applying Artificial Neural Networks for Face Recognition", Advances in Artificial Neural Systems, Volume 2011, ID: 673016.

[9] Masters, G. M. and W. Ela., 1991, "Introduction to environmental engineering and science", Prentice Hall Englewood Cliffs, NJ.

[10] Mehdizadeh, B. and K. Movagharnejad, 2011, "A comparison between neural network method and semiempirical equations to predict the solubility of different compounds in supercritical carbon dioxide", Fluid Phase Equilibria, 303 (1), 40-44.

[11] Movagharnejad, K. and M. Nikzad. 2007, "Modeling of tomato drying using artificial neural network." Computers and electronics in agriculture 59(1-2): 78-85, November.

[12] Rosenblatt, F. 1958, The perceptron: a theory of statistical separability in cognitive systems (Project Para), Cornell Aeronautical Laboratory.

[13] Sen R. 2010,"Surfactin: biosynthesis, genetics and potential applications." Biosurfactants: 316-323.

[14] Sen R. 2008, "Biotechnology in petroleum recovery: The microbial EOR." Progress in energy and combustion science 34(6): 714-724.

[15] Tang, K. W. and H. J. Chen., 1994, "A comparative study of basic backpropagation and backpropagation through time algorithms", Technical Report TR-700, State University of NY at Stony Brook, College of Engineering and Applied Sciences.
[16] Vamsidhar, E., K. Varma, et al. 2012, "Prediction of rainfall using backpropagation neural network model." International Journal on Computer Science and Engineering 2(4): 1119-1121.

[17] A. Soudmand-asli, S.shahab Ayatollahi, H.Mohabatkar, M. Zareie, S. F. shariatpanahi, 2007, 'the in situ microbial enhanced oil recovery in fractured porous media', Journal of Petroleum and Engineering.

[18] Gregory A. bala, Karen B. Barrett, Sandra L. Eastman, 1993, " MEOR and wettability research program", Idaho national Engineering Laboratory.

[19] R.S. Bryant, J. Douglass, 1985, " significance of the survival and performance of bacillus species in porous media for enhanced oil recovery', National Institute for Petroleum and Energy Research, topical report.

[20] Tawficabdulsalamobeida, norman, Oklahoma, 1990, " Microbial enhanced oil recovery at simulated subsurface reservoir conditions", $\mathrm{PhD}$ thesis.

[21] R.S. Bryant, J. Douglass, 1985, " significance of the survival and performance of bacillus species in porous media for enhanced oil recovery', National Institute for Petroleum and Energy Research, topical report.

[22] Soudmand-asli, S. Shahabayatollahi, H. Mohabatkar, M Zareie, S. F. Shariatpanahi, 2007, 'the in situ microbial enhanced oil recovery in fractured porous media", Journal of Petroleum and Engineering.

[23] M.R. Adelzadeh, R. Roostaazad, T. Bagherilotfabad, M.R. Kamali, 2012, " A Technical Feasibility Analysis to Apply Pseudomonas eroginosa",scientia iranica.

[24] Qingxin Li, Congbao Kang, Hao Wang, Chunde Liu, and ChangkaiZhang, 2002, "Application of microbial enhanced oil recovery technique to daqing oilfield", Biochemical Engineering journal.

[25] Tawficabdulsalamobeida, norman, Oklahoma, 1990, "' Microbial enhanced oil recovery at simulated subsurface reservoir conditions', $\mathrm{PhD}$ thesis.

[26] K. Behlülgilm. T. Mehmetogæ Lu, 2002, '’Bacteria for Improvement of Oil Recovery", Energy sources Journal. 